05

\title{
Периодическая последовательность фемтосекундных импульсов с селектируемой разностью фаз между огибающей и несущей
}

\author{
(C) Н.Н. Головин ${ }^{1}$, Н.И. Дмитриева ${ }^{1}$, Е.А. Горохов ${ }^{1}$, А.К. Дмитриев ${ }^{1,2}$ \\ ${ }^{1}$ Новосибирский государственный технический университет, \\ 630073 Новосибирск, Россия \\ ${ }^{2}$ Институт лазерной фризики Сибирского отделения РАН, \\ 630090 Новосибирск, Россия \\ e-mail: n.golovin@corp.nstu.ru
}

Поступила в редакцию 13.02.2019 г.

В окончательной редакции 16.04.2019 г.

Принята к публикации 23.04.2019 г.

Предложены метод и схема получения последовательности фемтосекундных импульсов без сдвига частотной гребенки с селектируемой разностью фаз между огибающей и несущей.

Ключевые слова: фемтосекундный лазер, сдвиг частотной гребенки, частота повторения импульсов, разность фаз между огибающей и несущей.

DOI: $10.21883 /$ OS.2019.09.48200.74-19

\section{Введение}

Разработка методов расширения спектра излучения фемтосекундного лазера свыше октавы позволила создать так называемый $f-2 f$-интерферометр, что обеспечило возможность измерения сдвига гребенки частот и, следовательно, обеспечить измерения оптических частот с погрешностью, не превышающей параметры лучших современных стандартов частоты [1-4]. Использование $2 f-3 f$ - и $3 f-4 f$-интерферометров существенно снижает требования к уширению спектральной линии излучения лазера [5]. Если частота повторения импульсов и сдвиг гребенки привязаны к частоте микроволнового стандарта, то весь ряд значений частотных компонент в излучении фемтосекундного лазера становится заданным, однако при этом имеет место разность фаз между огибающей и несущей для соседних импульсов, определяемая сдвигом гребенки. Вместе с тем была продемонстрирована возможность измерения сдвига гребенки частот лазеров с самосинхронизацией мод $\mathrm{c}$ произвольной шириной спектра излучения по смещению полос пропускания интерферометра Фабри-Перо [6-8]. Использование комплекса, состоящего из стандарта частоты, фемтосекундного синтезатора и интерферометра, позволяет создать единый стандарт времени, частоты и длины $[9,10]$.

При коротких импульсах, когда длительность импульса одного порядка с длиной волны, сдвиг фазы между огибающей и несущей существенно влияет на эффективность преобразования частоты в нелинейных оптических процессах, что чрезвычайно важно для получения аттосекундных импульсов [11-13]. Кроме того, отсутствие сдвига гребенки фемтосекундного лазера упрощает процесс измерения частот, поскольку при этом необходимо определять только частоту повторения импульсов. Применение лазера-гетеродина позволяет устранить сдвиг частотной гребенки фемтосекундного лазера [1]. Однако для реализации такой схемы необходимо, чтобы частота лазера-гетеродина лежала в низкочастотной области спектра излучения фемтосекундных импульсов, а его вторая гармоника попадала в высокочастотную часть спектра. Получение последовательности идентичных фемтосекундных импульсов с помощью смещения гребенки частот акустооптическим модулятором было продемонстрировано в работе [14].

В настоящей работе предложены метод и схема получения последовательности фемтосекундных импульсов без сдвига частотной гребенки с селектируемой разностью фаз между огибающей и несущей.

\section{Особенности излучения фемтосекундного лазера}

Излучение лазера с самосинхронизацией мод представляет собой электромагнитное колебание на частоте $v_{0}$ вблизи максимума линии усиления с амплитудной модуляцией, период которой равен времени обхода импульсом резонатора лазера $T$, при этом частота повторения импульсов $f=1 / T$, а напряженность поля

$$
E=\sum_{i=1}^{\infty} E_{0} \exp \left(-\left[\frac{t-\left(t_{0}+i T\right)}{\tau}\right]^{2}\right) \cos \left(2 \pi \nu_{0} t+\varphi_{0}\right)
$$

Здесь $t$ - текущее время, $t_{0}-$ точка отсчета на временной шкале, $\varphi_{0}-$ фаза несущей при $t=t_{0}, i-$ номер импульса.

На рис. 1, $a$ представлена временная последовательность фемтосекундных импульсов при сдвиге частотной 
гребенки $\Delta=f / 3$. Длительность импульсов $\tau$ ограничена спектральной шириной фемтосекундного излучения $\omega$, а число оптических колебаний в импульсе определяется отношением длительности импульсов $\tau$ к периоду световых колебаний $1 / v_{0}$. В пространственном представлении расстояние между импульсами в вакууме в отсутствие дифракционной расходимости равно оптической длине полного обхода резонатора лазера $L$. Отсюда возникает другое представление частоты повторения импульсов: $f=c / L$, где $c-$ групповая скорость света. В общем случае между огибающей и несущей имеется некоторый фазовый сдвиг $\varphi$. Скольжение разности фаз между несущей и огибающей $\varphi$ для соседних $(i+1)$-го и $i$-го импульсов равно

$$
\Phi=\varphi_{i+1}-\varphi_{i}=2 \pi \Delta / f
$$

Спектр излучения такого лазера представляет собой набор эквидистантно расположенных частот, интервал между которыми равен частоте повторения импульсов $f$ при сдвиге частотной гребенки лазера $\Delta$ (рис. $1, b)$.

Обычно сдвиг гребенки объясняется различием групповой и фазовой скоростей. С другой стороны, этот сдвиг можно объяснить тем, что отношение частоты несущей $v_{0}$ и частоты повторения импульсов $f$ в общем случае отлично от целого числа, что приводит к изменению разности фаз несущей относительно огибающей для соседних импульсов. Отметим, что в отсутствие сдвига гребенки частот в общем случае будет иметь место произвольный сдвиг фазы несущей относительно огибающей, при этом он будет одинаковым для всех импульсов.
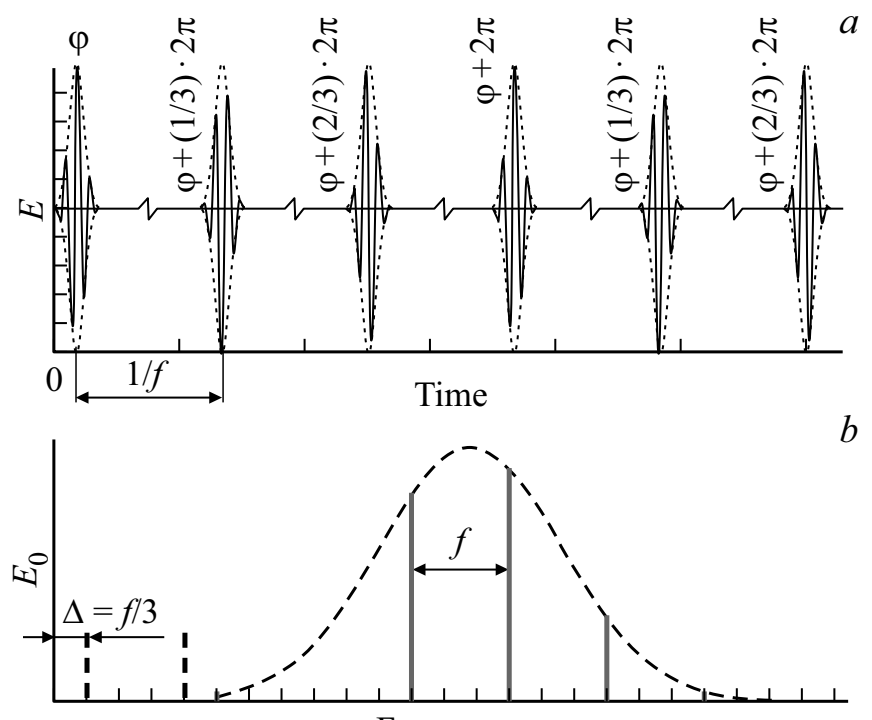

Frequency

Рис. 1. Последовательность фемтосекундных импульсов (a) и их спектр излучения $(b)$.

\section{Метод создания фемтосекундного излучения без сдвига частотной гребенки}

Разность фаз огибающей и несущей между $(i+k)$-м и $i$-м импульсами будет равна

$$
\Phi k=2 \pi \Delta k / f .
$$

Если эта разность фаз удовлетворяет условию

$$
\Phi k=2 \pi q,
$$

где $k$ и $q$ - целые числа, разности фаз огибающей и несущей между $(i+k)$-м и $i$-м импульсами будут кратны величине $2 \pi$, т. е. эти импульсы будут идентичны. При использовании соотношений (3) и (4) получим необходимые требования для создания фемтосекундных импульсов без скольжения фазы несущей относительно огибающей от импульса к импульсу:

$$
k / q=f / \Delta .
$$

Таким образом, при выделении из излучения фемтосекундного лазера каждого $k$-го импульса при соблюдении соотношения (5) получается периодическая последовательность идентичных импульсов на частоте повторения:

$$
F=f / k \text {. }
$$

При этом сдвиг синтезированной гребенки будет равен нулю, так что спектр излучения представляет набор частот

$$
v_{p}=j F,
$$

где $j$ - целое положительное число, а число составляющих спектра в $k$ раз больше по сравнению с излучением на выходе фемтосекундного лазера при неизменной ширине спектра.

Из всех возможных последовательностей импульсов сдвиг фазы несущей относительно огибающей $\varphi$ можно устанавливать с дискретностью $2 \pi / k$. Минимальные значения временного, а также пространственного интервалов между импульсами в синтезированной последовательности реализуются при $k=3$, когда $\delta= \pm 1 / 3$. На рис. 2, a представлена последовательность таких фемтосекундных импульсов. По сравнению с излучением фемтосекундного лазера (рис. $1, a$ ) в синтезированном излучении интервал между импульсами возрастает в 3 раза, в то время как частотный интервал между спектральными составляющими становится в 3 раза меньше, а разность фаз огибающей и несущей для каждого импульса становится неизменной, что приводит к ситуации, когда сдвиг гребенки частот отсутствует (рис. $2, b$ ). Отметим, что при неизменной интенсивности отдельных импульсов средняя мощность излучения будет падать. 


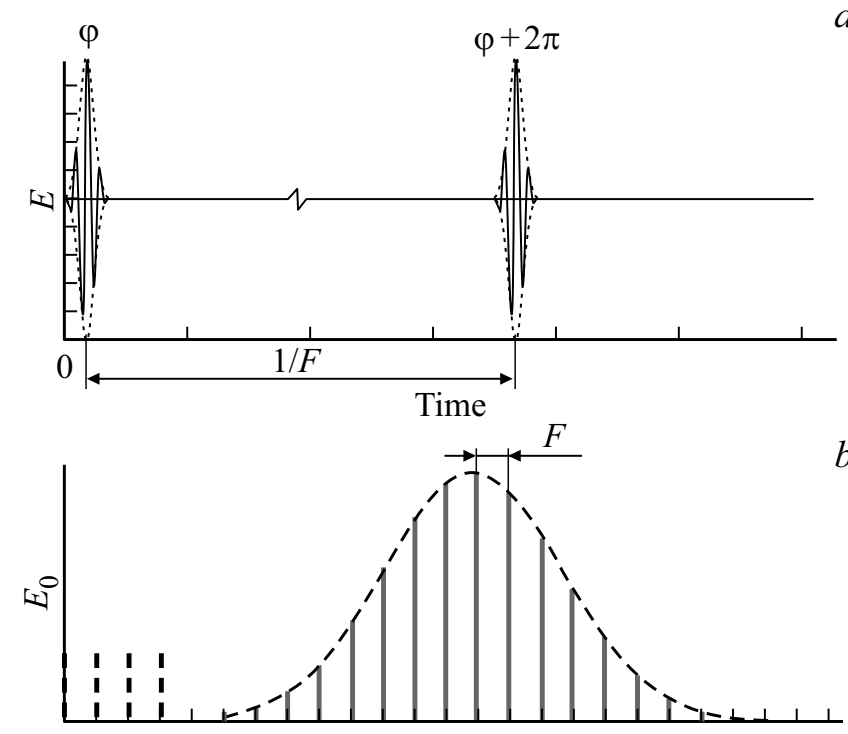

Frequency

Рис. 2. Периодическая последовательность синтезированных фемтосекундных импульсов $(a)$ и их спектр излучения $(b)$.

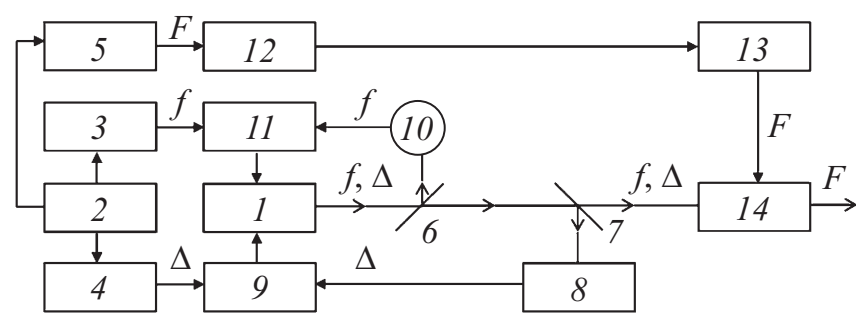

Рис. 3. Функциональная схема формирователя излучения без сдвига частотной гребенки: 1 - фемтосекундный лазер; 2 - стандарт частоты; 3 - синтезатор опорной частоты повторения импульсов фемтосекундного лазера $f ; 4-$ синтезатор опорной частоты сдвига гребенки $\Delta ; 5-$ синтезатор опорной частоты повторения синтезированной последовательности импульсов $F ; 6,7-$ делительные зеркала; $8-f-2 f$ интерферометр; 9 - блок фазовой привязки сдвига частотной гребенки излучения фемтосекундного лазера; 10 - фотодетектор; 11 - блок фазовой привязки частоты повторения импульсов фемтосекундного лазера; 12 - фазовращатель; $13-$ формирователь импульсов; 14 - модулятор интенсивности.

\section{Формирование последовательности идентичных фемтосекундных импульсов с управляемой разностью фаз между несущей и огибающей}

Функциональная схема формирователя излучения без сдвига частотной гребенки представлена на рис. 3. Для стабилизации параметров фемтосекундного лазера и синтезированной последовательности импульсов используются синтезаторы опорной частоты повторения импульсов $f(3)$, сдвига гребенки $\Delta$ (4) фемтосекундного лазера и частоты повторения синтезирован- ной последовательности импульсов $F(5)$. В качестве опорной для всех синтезаторов используется частота стандарта (2), что позволяет синхронизовать по фазе частоты $f$ и $F$.

Частота повторения импульсов $f$, выделяемая на фотодетекторе (10), подается на блок фазовой привязки частоты (11), куда также поступает сигнал на частоте $f$ от синтезатора (3), что позволяет осуществлять стабилизацию частоты повторения импульсов.

Сигнал на частоте сдвига гребенки фемтосекундного лазера $\Delta$, выделяемый с помощью $f-2 f$-интерферометра (8), подается на один из входов блока фазовой привязки частоты (9), на другой вход которого поступает сигнал от синтезатора частоты (4). Значение частоты последнего должно удовлетворять условию (5). Таким образом, осуществляется фазовая привязка частотного сдвига.

Сигнал на частоте $F$, значение которой удовлетворяет условию (6), задается синтезатором (5). Этот сигнал через фазовращатель (12) подается на формирователь импульсов (13), который управляет модулятором интенсивности (14). Длительность управляющих импульсов должна быть существенно меньше временного интервала между импульсами фемтосекундного лазера. Это обеспечивает „чистое“ выделение из первоначальной последовательности импульсов каждого $k$-го импульса. C помощью фазовращателя фаза управляющего модулятором сигнала подстраивается таким образом, чтобы интенсивность прошедшего через него излучения фемтосекундного лазера была максимальной. Таким образом, на выходе модулятора формируется излучение с частотой повторения импульсов $F$ без сдвига частотной гребенки. Если после этого перестраивать фазу управляющего сигнала с шагом $2 \pi / k$, можно синтезировать последовательности с различным сдвигом фазы несущей относительно огибающей. Например, если $k=3$, как на рис. 1 , то, изменяя фазу управляющего сигнала на величину $2 \pi / 3$, можно получить три различные последовательности: со сдвигом фазы несущей относительно огибающей, равным $\varphi$, или $\varphi+2 \pi / 3$, или $\varphi+4 \pi / 3$. Дискретность установки фазы несущей относительно огибающей можно уменьшить за счет увеличения $k$.

\section{Заключение}

Предложены способ и схема формирования последовательности фемтосекундных импульсов без сдвига частотной гребенки с управляемой разностью фаз между огибающей и несущей. Из всех возможных последовательностей импульсов сдвиг фазы несущей относительно огибающей $\varphi$ можно устанавливать с дискретностью $2 \pi / k$. 


\section{Финансирование работы}

Работа выполнена при финансовой поддержке гранта Министерства науки и высшего образования РФ в рамках базовой части государственного задания № 3.6835.2017/8.9 и гранта Российского фонда фундаментальных исследований № 18-02-00316.

\section{Конфликт интересов}

Авторы заявляют, что у них нет конфликта интересов.

\section{Список литературы}

[1] Udem Th., Reichert J. Holzwarth R., Hansch T.W. // Phys. Rev. Lett. 1999. V. 82. P. 3568. doi 10.1103/PhysRevLett.82.3568

[2] Diddams S.A., Jones D.J., Ye Jun, Cundiff S.T., Hall J.L., Ranka J.K., Windeler R,S., Holzwarth R., Udem Th., Hansch T.W. // Phys. Rev. Lett. 2000. V. 84. P. 5102. doi 10.1103/PhysRevLett.84.5102.

[3] Bagayev S.N, Dmitriyev A.K., Chepurov S.V., Dychkov A.S., Klementyev V.M., Kolker D.B., Kuznetsov S.A., Matyugin Yu.A., Okhapkin M.V., Pivtsov V.S., Skvortsov M.N., Zakharyash V.F., Birks T.A., Wadsworth W.J., Russel P.St.J., Zheltikov A.M. // Laser Phys. 2001. V. 11. P. 1270.

[4] Beverini N., Carelli G., De Michele A., Maccioni E., Nyushkov B., Sorrentino F., Moretti A. // Opt. Lett. 2005. V. 30. N 1. P. 32. doi 10.1364/OL.30.000032

[5] Telle H.R., Steinmeyer G., Dunlop A.E., Stenger J., Sutter D.H., Keller U. // Appl. Phys. B. 1999. V. 69. P. 327. doi $10.1007 / \mathrm{s} 003400050813$

[6] Jones R.J., Diels J-C., Jasapara J., Rudolph W. // Opt. Commun. 2000. V. 175. P. 409. doi 10.1016/S00304018(00)00483-1

[7] Баснак Д.В., Бикмухаметов К.А., Дмитриев А.К., Дмитриева Н.И., Луговой А.А., Покасов П.В., Чепуров С.B. // Квант. электрон. 2010. Т. 40. № 8. C. 733; Basnak D.V., Bikmukhametov K.A., Dmitriev A.K., Dmitrieva N.I., Lugovoi A.A., Pokasov P.V., Chepurov S.V. // Quant. Electron. 2010. V. 40. N 8. P. 733. doi 10.1070/QE2010v040n08ABEH014354

[8] Баснак Д.В., Бикмухаметов К.А., Дычков А.С., Кузнецов С.А., Луговой А.А., Мицзити П. // Квант. электрон. 2012. T. 42. № 1. C. 71; Basnak D.V., Bikmukhametov K.A., Dmitriev A.K., Dychkov A.S., Kuznetsov S.A., Lugovoy A.A., Mitsziti P. // Quant. Electron. 2012. V. 42. N 1. P. 71. doi 10.1070/QE2012v042n01ABEH014748

[9] Бакланов Е.В., Дмитриев А.К. // Квант. электрон. 2002. T. 32. № 10. C. 925; Baklanov E.V., Dmitriev A.K. // Quant. Electron. 2002. V. 32. N 10. P. 925. doi 10.1070/QE2002v032n10ABEH002319

[10] Баснак Д.В., Дмитриев А.К., Луговой А.А., Покасов П.В. // Квант. электрон. 2008. Т. 38. № 2. C. 187; Basnak D.V., Dmitriev A.K., Lugovoy A.A., Pokasov P.V. // Quant. Electron. 2002. V. 38. N 2. P. 187. doi 10.1070/QE2008v038n02ABEH013635

[11] Bohan A.D., Antoine P., Milosevic D.B., Piraux B. // Phys. Rev. Lett. 1998. V. 81. P. 1837. doi 10.1103/PhysRevLett.81.1837
[12] Ivanov M., Corcum P.B., Zuo T., Bandrauk A. // Phys. Rev. Lett. 1995. V. 74. P. 2933. doi 10.1103/PhysRevLett.74.2933

[13] Christov I.P., Murnane M.M., Kapteyn H.C. // Phys. Rev. Lett. 1997. V. 78. P. 1251. doi 10.1103/PhysRevLett.78.1251

[14] Jones D.J., Diddams S.A., Ranka J.K., Stentz A., Win eler R.S., Hall J.L., Cundiff S.T. // Science. 2000. V. 288. P. 635. doi 10.1126/science.288.5466.635 